\title{
Platform-mediated reputation systems in the sharing economy and incentives to provide service quality: the case of ridesharing services
}

This is the peer reviewed version of the following article:

Original:

Basili, M., Alessandra Rossi, M. (2020). Platform-mediated reputation systems in the sharing economy and incentives to provide service quality: the case of ridesharing services. ELECTRONIC COMMERCE RESEARCH AND APPLICATIONS, 39(Jan.-Feb.), 1-11 [10.1016/j.elerap.2019.100835].

Availability:

This version is availablehttp://hdl.handle.net/11365/1073852

since 2019-06-11T13:11:05Z

\section{Published:}

DOI:10.1016/j.elerap.2019.100835

Terms of use:

Open Access

The terms and conditions for the reuse of this version of the manuscript are specified in the publishing policy. Works made available under a Creative Commons license can be used according to the terms and conditions of said license.

For all terms of use and more information see the publisher's website.

(Article begins on next page) 


\section{Accepted Manuscript}

Platform-mediated reputation systems in the sharing economy and incentives to provide service quality: the case of ridesharing services

Marcello Basili, Maria Alessandra Rossi

PII:

S1567-4223(19)30012-2

DOI: https://doi.org/10.1016/j.elerap.2019.100835

Article Number: 100835

Reference: ELERAP 100835

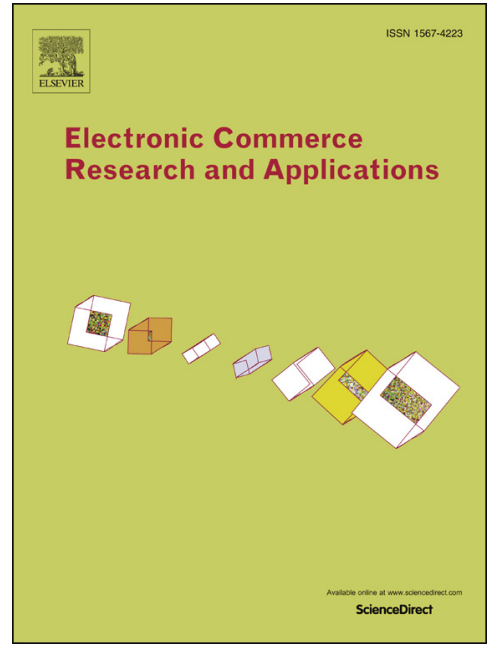

To appear in:

Electronic Commerce Research and Applications

Received Date:

31 May 2018

Revised Date:

3 January 2019

Accepted Date:

8 February 2019

Please cite this article as: M. Basili, M.A. Rossi, Platform-mediated reputation systems in the sharing economy and incentives to provide service quality: the case of ridesharing services, Electronic Commerce Research and Applications (2019), doi: https://doi.org/10.1016/j.elerap.2019.100835

This is a PDF file of an unedited manuscript that has been accepted for publication. As a service to our customers we are providing this early version of the manuscript. The manuscript will undergo copyediting, typesetting, and review of the resulting proof before it is published in its final form. Please note that during the production process errors may be discovered which could affect the content, and all legal disclaimers that apply to the journal pertain. 


\title{
Platform-mediated reputation systems in the sharing economy and incentives to provide service quality: the case of ridesharing services
}

\author{
Marcello Basili \\ Department of Economics and Statistics, University of Siena, Italy \\ Maria Alessandra Rossi ${ }^{*}$ \\ Department of Economics, University of Chieti-Pescara
}

\begin{abstract}
Sharing economy platforms often use reputation systems to actively perform a 'regulatory'/control role, by excluding from access to the platform users with ratings below a given threshold. We provide a multiple case study analysis of 9 platforms and investigate through a simple inter-temporal choice model the effect of the design of this specific application of online rating systems on users/providers' incentives to ensure a high level of service quality. Compliance with the platform's behavioural rules is imperfect even with perfect reviews and even if riders cannot switch across platforms. It can be increased by linking remuneration to performance and by increasing the opportunity cost of reintegrating the endowment of reputation, also by influencing providers' perception of the magnitude of this cost. Thus, there may be an efficiency rationale for the controversial choice to willingly preserve riders' uncertainty as to the operation of the algorithm and for portability of reputation.
\end{abstract}

Keywords: sharing economy, shared mobility, reputation systems, ridesourcing, incentives, service quality, self-regulation.

\footnotetext{
* Corresponding author: Department of Economics, University of Chieti-Pescara, viale Pindaro 42, 65127 Pescara, Italy. Tel.: +39 085 4537575; Fax: +39 085 4537639; Email address: alessandra.rossi@unich.it.
} 


\section{INTRODUCTION}

Reputation systems (also called feedback or rating systems) have been acknowledged as a key feature of the institutional environment enabling online transactions since the early days of the Internet, given the role they play in sustaining trust in interactions among strangers along with brand image and public regulation (Resnick et al., 2000; Tadelis, 2016).

The emergence of the so-called sharing (peer-to-peer/P2P or collaborative) economy has made the role of rating systems even more salient. The sharing economy involves on-demand provision of goods and services among peers holding underutilized resources (in terms of time, skills, capital goods etc.) mediated by a platform (e.g., Einav et al., 2016; Horton et al., 2015; Sundararajan, 2016)2

Mutual trust is clearly an indispensable enabler of such collaborative interactions (Hawlitschek et al., 2018; Mazzella et al., 2016). Platforms depend on a two- or multi-sided business model, and therefore on their ability to harness network effects by attracting a large number of users on the different sides. Moreover, given that they lower barriers to entry to non-professional users/providers as compared to similar non-P2P services, service provision through platforms necessarily exhibits a wider variance in the distribution of quality, which may sometimes jeopardize users' trust in the platform.

Trust is also hard to sustain in P2P platforms with the standard tools of brand image and public regulation. Indeed, brand image of service providers is less well established as a trust-building device when platform users are not professionals ${ }^{3}$, and standard public regulatory tools meant to ensure consumer protection have not so far been extensively applied to the sharing economy (Schor and Fitzmaurice, 2015). Moreover, the adverse consequences of service providers' misbehaviour in P2P online interactions may sometimes be more pernicious than those involved in standard online sales: for instance, trusting an unreliable provider of a ridesharing service may, in extreme circumstances, cause users physical damage, while the consequences of relying on a bogus online seller have typically the nature of a monetary loss (ter Huurne et al., 2017).

\footnotetext{
${ }^{2} \mathrm{We}$ acknowledge the existence of a multiplicity of views as regards the definition of the sharing economy (Botsman, 2013). The definition here provided is coherent with the purposes of this paper.

${ }^{3}$ Evidence exists, however, that personal branding plays a key role in boosting popularity in the context of sharing economy applications in the hospitality sector (Mauri et al., 2018).
} 
Thus, P2P platforms actively seek to build and maintain trust among their users, and the establishment of effective reputation systems plays a key role in this regard (Katz, 2015; Thierer et al., 2015). Sometimes, their choices in the overall design of rating systems have also been rather controversial, especially in the context of shared mobility, where Uber actively exercises regulatorylike functions by deactivating providers from access to the platform according to "rules" that are vocally condemned as too opaque from providers themselves (Bercovici, 2014). For instance, the threshold of ratings that triggers expulsion is often unclear, as well as the mechanism by which the platform's algorithm computes reputational ratings.

Reputation systems, both generally in online marketplaces and specifically in P2P platforms, have been the object of a substantial amount of research from various disciplines, including economics, management, information systems, electronic commerce research and computing. Economics and management contributions have mostly focused on issues of truthful revelation of evaluations, biases in the gathering and aggregation of consumer reviews, strategic manipulation of information by online sellers and economic effects of online reputation on sales or other business metrics (see also Luca, 2016 for an overview). Thus, this literature mostly explores the incentive effects of the design of rating systems on platform users/buyers (providers of user feedback) and has so far largely disregarded the incentive effects of the design of the rating system on the quality of service provision by platform users/providers (in the context of this paper, also drivers).

The electronic commerce and information systems literatures have also devoted attention to reputation systems, in the context of the broader research field on platform ecosystems design and governance. As mentioned, reputation systems are one of the key antecedents of trust, together with, e.g., trust in the platform itself and interaction experience, although scholars highlight that trust is considerably more complex and clearly extends beyond reputation per se (ter Huurne et al., 2017). Research has focused, on one side, on the impact of reputation indicators on trust towards platforms and providers (see, e.g., Ba and Pavlou, 2002; Bente et al., 2014; Ert et al., 2016; Li et al., 2016). On the other side, it has explored the behaviour of online reviewers, and particularly incentives to encourage provision of reviews, robustness, truthfulness of the reputation information as well as the metrics used to compute and aggregate feedbacks (for an early survey, see Jøsang et al., 2007). 
More generally, the design of rating systems may also be considered an essential ingredient of control, one of the three key dimensions of platform governance according to Tiwana et al. (2010) and Tiwana (2014), i.e. the means through which the platform owner ensures that behaviour of providers/complementors is aligned to the best interest of the platform. In particular, reputation systems may be used by platform owners as a way to implement control via 'gatekeeping', 'process control' and 'metrics' (Tiwana, 2014), something the economics/management literature refers to as an instance of centrally organized 'regulatory' function performed by the platform, and specifically as the platform's role as private 'licensing authority' (Boudreau and Hagiu, 2009; Evans, 2011). This occurs particularly when platform owners exercise the power to exclude from access to the platform users whose online rating/reputation falls below a given threshold.

In this paper, we analyse the governance choices of sharing mobility platforms as regards reputation systems. We first perform a multiple case study analysis of 9 platforms, so as to highlight their current features in terms of design and governance of feedback systems. Among other things, the analysis indicates the existence of varied combinations of choices as regards the design of rating systems and the use of reputation information across platforms. It also suggests that shared mobility platforms do not currently make substantial recourse to explicit incentive systems linking remuneration to performance.

We subsequently propose a simple theoretical model that aims to capture the effect of the design of online rating systems backed by the threat of exclusion from the platform on providers' incentives to comply with the behavioural standards set by the platform or, more generally, to ensure a high level of service quality. We think that providers/drivers' incentives to offer service quality can be analysed as a standard optimal inter-temporal choice problem, where the driver has a two arguments utility function (Dardanoni, 1988), indeed consumption of standard goods and reputation, which can be considered as an independent variable (see also Basili et al., 2015). We consider two alternative settings: one in which drivers cannot switch to a different platform, and another in which they have the possibility of switching to alternative platforms.

The model allows to derive a number of implications for the design of control mechanisms by sharing platforms. We find that the threat of exclusion from the platform, i.e., the active exercise of 
the 'gatekeeping' role of platforms, is not liable per se to induce perfect compliance, even if ratings can perfectly capture quality and even if drivers cannot switch to a different platform. This is relevant for the debate on the regulation of P2P platforms, a crucial aspect of which concerns the effectiveness of their embedded reputation system in addressing asymmetric information-related issues.

In this regard, we highlight that an increase in compliance may be achieved by linking remuneration to performance and by increasing the opportunity cost of reintegrating the endowment of reputation. The latter can be obtained either by appropriate design of the centralized assignment algorithm, or by influencing providers' perception of the magnitude of this cost. This, in turn, suggests that there may be an efficiency rationale for the choice to willingly preserve riders' uncertainty as to the operation of the algorithm, i.e. to increase the perceived cost of restoring reputation.

Finally, we show that the possibility of free switching across platforms makes the design of the rating system (i.e., the choice of the rating threshold below which drivers are excluded from the platform, as well as the scale of ratings) irrelevant as an incentive device since providers can acquire a new endowment of reputation simply by switching across different platforms. Existence of such strategic behaviour suggests that it may be in the platform's interest to devise ways to reduce providers' ability to acquire a new endowment of reputation through switching such as, for instance, by requiring reputation to be portable and by imposing to drivers losing their reputation on one platform a period of 'incapacitation', i.e., of suspension from the possibility to work for any platform.

The paper is organized as follows. Section 2 provides some background on the relevant economics, management, information systems and electronic commerce literature. Section 3 highlights the main features of platform-mediated rating systems in shared mobility so as to set the stage for the simple model proposed in Section 4. Section 5 discusses its policy implications.

\section{BACKGROUND}

Aspects of online trust and reputation systems have been explored by a variety of disciplines. This paper focuses on the perspectives provided by economics, management, information systems and electronic commerce research, as it seeks to provide insights that, elaborated on the basis of a simple economic model, may be of relevance for both economic and information systems approaches. 
The main themes of the economics and management research concern the issue whether reputation systems can be considered a reliable source of quality information for users/buyers and the ways in which their design can be improved so as to prevent biases in the ratings the latter provide. Scholars have explored incentives to provide ratings, which are public goods likely to be underprovided (Avery et al., 1999; Miller et al., 2005); biases due to the self-selection of rating providers (Dellarocas and Wood, 2008; Nosko and Tadelis, 2015); strategic behaviours in rating (e.g., misrepresentation for fear of retaliation (Bolton et al., 2013; Cabral and Hortacsu, 2010); and the influence of empaty and social relationships on ratings (Andreoni and Rao, 2011).

Among the key results of these analyses is the recognition of biases inherent in the adoption of two-way or reciprocal rating systems (i.e., of rating systems where buyers and sellers review each other, as opposed to one-way rating systems where only one side of the market can rate the other). For instance, in the sharing economy context, Lauterbach et al. (2009) and Overgoor et al. (2011) analyse reputation systems in CouchSurfing websites, highlighting biases toward positive reviews and the possibility of collusive reciprocity. Zervas et al. (2015) reach similar conclusions by comparing TripAdvisor and Airbnb. Horton et al. (2015) also highlight the phenomenon of rating inflation through a laboratory experiment on the platform Elance oDesk.

To address these problems within reciprocal reputation systems, authors have explored the tool of simultaneous revelation of reviews, which mitigates strategic incentives without fully eliminating them (Bolton et al., 2013; Fradkin et al., 2015). Other design features explored to address the phenomenon of "grade inflation" associated to the fear of retaliation relate to whether ratings and reviews can be linked to the user who has formulated them and immediately accessible, whether they are anonymous, or formulated in a double blind system (for an overview, see Tadelis, 2016).

Other studies focus on the nature and timing of publication of users' information. The key issue that emerges in this regard concerns discriminatory behaviour related to gender and/or ethnicity and has been explored both in general in the context of online market places (Nunley et al., 2011) and specifically in the sharing economy context (Edelman et al., 2017; Edelman and Luca, 2014).

Much less attention has been devoted to the use that platforms may make of reputation systems for the purpose of providing incentives. At a descriptive level, Evans (2012) stresses the 'regulatory' 
role performed by platforms also through the use of rating systems and their ability to internalize externalities across multiple sides. Dai et al. (2018) consider ways in which platforms may aggregate reviews so as to increase their informational content (and therefore their ability to 'guide' users' choices so as to reward positive behaviour). Finally, Nosko and Tadelis (2015) propose to integrate a measure of ratings in search rankings so as to increase buyers' exposure to higher quality sellers and downgrade lower quality sellers. They run an experiment on eBay, to implement their proposed solution, finding a positive impact on consumer experience and success of the platform.

Some of the themes addressed by the above-described research have received significant attention also in the information systems and electronic commerce literature. The importance of reputation systems as one of the antecedents of trust in online exchange environments is well recognized (Hendrikx et al., 2015; ter Huurne et al., 2017; Teubner et al., 2017). Reputation indicators such as reputation scores, ratings, and textual reviews have been shown to have a positive impact on trust towards the platform and sellers and on sales (Ba and Pavlou, 2002; Bente et al., 2014; Ert et al., 2016; Li et al., 2016).

Problems in the generation of reviews such as feedback under-provision, negative-review reluctance, dishonest reports, social influence bias, selection bias and rating inflation have also been thoroughly documented (see, e.g., de Langhe et al., 2016; Resnick et al., 2000). Much attention has been devoted to more fine-grained platform design issues than those addressed by the economics and management literature, in an attempt to improve performance (Jøsang et al., 2007; Liu and Munro, 2012; Malaga and Smith, 2001). Some studies have specifically dealt with the use of reputationsystem-related incentives by platforms, focusing on incentives to users-reviewers, provided to increase the quality of reviews (Chen et al., 2017; Jurca and Faltings, 2003; Zhao et al., 2012). Gregg and Scott (2006) explore the role of reputation systems in reducing online auction fraud, thus highlighting one facet of the impact of reputation on sellers' conduct. However, to our knowledge, the impact of reputation indicators on providers' behaviour and the scope for reputation-based incentive systems directed to providers has so far been much less prominent.

We believe further analysis of the use of reputation-based incentive systems by platforms as a means to increase compliance with the platform's behavioural rules by providers may contribute both 
to the economics and the information systems literature. In particular, simple economic modelling may provide insights relevant to the broader literature on platform and technology ecosystem governance, as developed for instance by Tiwana et al. (2010), Tiwana (2014) and Wareham et al. (2014). Reputation systems may be used by platform owners as a way to implement one of the essential elements of governance - control - via 'gatekeeping', 'process control' and 'metrics' (Tiwana, 2014, pp.123-125). In particular, ratings are one of the market-oriented 'metrics' that may be used to implement control. 'Gatekeeping' refers to the extent to which the platform sets predefined acceptance criteria to define who can participate to the activities mediated by the platform. Setting a rating threshold below which users are excluded from the platform may be interpreted as an instance of this type of control. Finally, 'process control' refers to the degree to which a platform owner rewards or penalizes users based on compliance with its predefined behavioural rules. Effective exercise of the right to deactivate users if their rating falls below a given threshold can be interpreted accordingly.

Reputation systems may also be considered relevant to addressing the control-autonomy tension highlighted by Wareham et al. (2014) in the context of technology ecosystem governance. While, however, the bulk of the mentioned literature refers to the governance of relationships between platforms and complementors that are software or app developers, the present paper considers issues of control in the less explored context of the relationship between platforms and providers of services different from software. This may be relevant given the changing inter-organizational relationships of information systems development, to reflect the emergence of platforms in highly diverse industries (De Reuver et al., 2018).

\section{Main Features Of Platform-Mediated Rating SySTEMS In SHARED}

\section{MOBILITY}

\subsection{SHARED MOBILITY PlatFormS’ bUSINESS MODELS}

Shared mobility services, together with shared hospitality services, represent the fastest growing segments of the sharing economy in terms of both popularity and revenues, and have catalysed the attention of many large traditional players of the automotive sector: both General Motors and Toyota 
have stakes in Lyft, the second ridesourcing company worldwide; BMW and Sixt have joined forces to create the B2C carsharing platform DriveNow; Daimler manages the platform MyTaxi.

The key attributes of the sharing economy apply also to the case of shared mobility services (Botsman, R. Rogers, 2010):

- Access over ownership - users/riders choose these services out of a preference for obtaining access to mobility services rather than ownership of vehicles;

- Peer-to-peer interactions - interactions and transactions mediated by shared mobility platforms often involve non-professional peers providing services;

- Allocation of idle resources - service provision through the platform often occurs through the mobilization of private resources that would otherwise remain underutilized.

The different business models adopted by shared mobility services combine some or all of the above features in different ways. One possible classification is reported in Table $1^{4}$.

\section{[INSERT TABLE 1 ABOUT HERE]}

All of the business models described enable access to transportation services as an alternative to car ownership. Sharing of access occurs in many forms (Standing et al., 2018): renting, lending or subscribing to a service (P2P carsharing), donating (when carsharing takes the form of carpooling with no payment involved) and purchase of a service (ridesharing, ridesourcing and hybrid services). Only the first three models involve also peer-to-peer interactions ${ }^{5}$ and allocation of privately held idle resources, the last category of shared mobility services (hybrid services) being entirely reliant on professional service providers and vehicles acquired for the purpose of providing a professional service.

Differences exist also with regard to the nature and/or form of payment foreseen by the different platforms and the degree of control the platform exerts over matching and over users (Constantiou et al., 2017). In the first two cases (P2P carsharing and ridesharing), interactions among users/providers and users/riders are mediated by a decentralized platform (Einav et al., 2016), i.e. matching among

\footnotetext{
${ }^{4}$ Slightly different classifications have been proposed, for instance, by Shaheen and Cohen (2018) and by Standing et al. (2018).

${ }^{5}$ This is not the case, however, when ridesourcing services are provided by professionals, as it happens with the service Uber Black.
} 
different groups of users of the platform occurs through the decentralized choices of users. Pricing choices (or, often, cost compensation choices) are also left to decentralized agreement among peers, mostly within limits set by the platform. For instance, BlaBlaCar drivers can only ask for a share of the operating costs incurred, within the limits of a cost calculation predefined by the platform. In the case of ridesourcing and hybrid services, by contrast, platforms are centralized, i.e. matching occurs through rules and procedures entirely determined by the platform. All important aspects of the ride, from quality features to pricing and payment, are also strictly controlled by the platform, who may use market-mimicking pricing methods such as "surge pricing" to reflect fluctuations in supply and demand and to provide incentives to both riders and drivers.

\subsection{SERVICE QUALITY AND REPUTATION SYSTEMS}

Particularly for the case of centralized platforms, a key parameter of competition is given by quality of service. Evidence exists that superior quality is an important driver of demand for ridesourcing services (Rayle et al., 2013) and that entry in a local transportation market of ridesourcing services determines an increase in quality of traditional services as well, as measured by the decline in complaints (Wallsten, 2015).

Some commentators attribute this feature of shared mobility platforms to their effectiveness in addressing the standard adverse selection and moral hazard problems characterizing transactions in the local transportation market, going as far as to say that this eliminates any economic rationale for public regulation (Thierer et al., 2015). In their view, this effectiveness derives, in turn, from the platforms' ability to efficiently use and aggregate information. The working of rating/reputation systems embedded into the platform is key in this regard.

Both centralized and decentralized platforms use some form of rating/reputation system. The main differences among the various systems observed on the market concern either features relating to how user information is collected and made available (i.e., nature and timing of publication of users' information and the nature of collected ratings) or features relating to how platforms use this information to design control/incentive systems (scale of ratings and thresholds for exclusion). All of 
these features affect the extent to which each platform's rating system is able to address different forms of users' opportunistic behaviour.

In the following, we illustrate the results of a multiple case study analysis of a selected sample of 9 shared mobility platforms, conducted on the basis of the evaluation of the terms of service and the FAQs of the different platforms, of users' blogs and information pages (such as, for instance, uberpeople.net), as well as Youtube videotutorials explaining the use of the platforms. The platforms considered are the following: Turo (https://turo.com), GetAround (www.getaround.com), Drivy (www.drivy.com), BlaBlaCar (www.blablacar.com), Liftshare (https://liftshare.com), Uber (www.uber.com), Lyft (www.lyft.com), GetTaxi (https://gett.com), MyTaxi (https://us.mytaxi.com).

The results of the analysis are summarized in Table 2 and further explained in what follows.

[INSERT TABLE 2 ABOUT HERE]

\section{Nature and timing of publication of users' information}

As for the nature and timing of publication of users' information, a first distinction is immediately apparent between decentralized and centralized platforms. Decentralized platforms publish a greater amount of information on their users from both sides of the market, even though they reveal it in full only once a transaction has been established. The same type of information is required to both users/providers and riders. Most platforms adopt procedures of certification and/or verification of the information users provide, using 'tags' to identify users whose information has been verified. Centralized platforms, by contrast, require a different amount of information from drivers and riders, gathering additional information from drivers (e.g., driving licence, existing civil or penal offences etc.). Drivers' personal information is verified by the platform, while no verification activity concerns riders (in the case of GetTaxi, riders can even use nicknames). Both drivers' and riders' information is available only after matching, and users can refuse the matching within 15 seconds. All the platforms analysed foresee links to Facebook and some also to other social media (with the exception of 
GetTaxi), both to make easier the registration procedure and as a way to convey additional information on users' reliability.

\section{Nature of ratings}

As mentioned in Section 2, two crucial distinctions among rating systems explored by the literature concern whether they are one-way or two-way and whether they are open, double blind or anonymous. Of the 9 platforms considered, only two have one-way rating systems - the hybrid services GetTaxi and MyTaxi. Of the remaining platforms, two have double blind systems (Turo and BlaBlaCar), two are open (Drivy and Lyftshare), two are anonymous (Uber and Lyft), and one (GetAround) uses ratings only internally, without publishing it in any way. Most platforms for which this information was available foresee a form of ex post control on ratings and feedbacks, to address instances of 'unfair' evaluation (Lyftshare, Uber and Lyft). Other two platforms foresee forms of control before publication instead (GetAround and BlaBlaCar).

\section{Scale of ratings}

Finally, and most importantly from the perspective of the present paper, it is important to consider the scale adopted for ratings and whether ratings are used to provide incentives and/or to exclude users from the platform. The majority of platforms adopts a scale from 1 to 5 , with some exceptions illustrated in Table 2. Publication of ratings can be considered one way through which ratings can be made to perform an incentive function. This is common for decentralized platforms (with the exception of GetAround), whereas in centralized platforms ratings are accessible only after a transaction has been established and users have a very short time horizon in which they can refuse to complete the transaction. In the latter type of platform, ratings may be linked to remuneration through appropriate design of the algorithm. For instance, on the MyTaxi platform higher ratings imply a higher probability of being assigned to higher value rides, while on the GetTaxi platform, ratings are used to create a ranking of all of the platforms' drivers of a city.

\section{Thresholds for exclusion}

Of the platforms considered, $\mathrm{P} 2 \mathrm{P}$ carsharing platforms and hybrid services platforms do not foresee any threshold of ratings triggering exclusion from the platform for either side of the market. 
Also Lyftshare, a ridesharing platform, does not foresee thresholds. The other, and more popular (with about 35 million subscribers) ridesharing platform - BlaBlaCar - foresees a rating threshold: users with average rating below 3 after at least 3 rides can be excluded from the platform. Thresholds for drivers (but not for riders) are also used, often controversially, by ridesourcing platforms - Uber and Lyft in our sample.

Uber adopts two thresholds. The first is based on ratings: users with average rating below a given threshold on the last 500 rides can be excluded from the platform. Importantly, the threshold is different in different cities, and is often not known to drivers. The actual working of this threshold is reported to be very opaque (see, for instance, Noopur Raval's response to the 2015 FTC consultation on ridesharing on behalf of academics and drivers of the ridesharing industry; FTC, 2015). Exclusion of drivers from the platform may be triggered also by an acceptance rate of rides that falls below $25 \%$.

Lyft, in turn, envisages a clearer rating threshold: users with an average rating below 4.77 on the last 100 rides can be excluded from the platform. To provide incentives to accept rides, by contrast, this platform uses positive incentives. Drivers are provided with a $20 \%$ increase in remuneration ("Power driver bonus", amounting to a reduction of the platform's commission) for drivers with acceptance rate above $90 \%$.

To summarize, the platforms considered do not appear to fully use rating systems as an incentive device. Only hybrid services envisage some form of explicit link between performance, as measured by ratings, and remuneration. Ridesourcing services rely more extensively on the negative incentive provided through the threat of exclusion from the platform, but do not foresee a transparent link between performance and remuneration. Moreover, in the case of Uber, rules governing exclusion from the platform are consistently reported to be non transparent to the point of appearing arbitrary. Finally, it is important to note that reputation is clearly not portable across platforms: once a driver's ratings have fallen below a given platform's threshold, the driver can normally switch to a different platform. The link to social networks foreseen by the majority of the platforms may to some extent create a cross-platform connection in terms of reputation, but this is of limited use for centralized platforms in which transactions are established in real time. 


\section{A MODEL OF THE OPTIMAL INTER-TEMPORAL CHOICE OF REPUTATION BY}

\section{DRIVERS}

The following simple model analyses the optimal inter-temporal choice of reputation, obtained through service quality provision, by users/drivers offering services through a P2P platform that administers a rating system based on users' reviews. It aims at highlighting the effect of different platform design choices on drivers' compliance with the platform's behavioural standards, under alternative hypotheses on the degree of ease of switching across platforms.

The model draws on consolidated insights from the well-established economic literature on principal-agent problems in the employment relationship and their solutions under risk and uncertainty and applies them in the relatively unexplored context of platform-drivers relationships. In particular, we elaborate on insights from the pay-for-performance literature (see, e.g., Fudenberg and Tirole, 1990; Holmstrom, 1979; Holmstrom and Milgrom, 1987; see also Gibbons and Roberts, 2010 for a surevey) and from the literature on career concerns (Dewatripont et al., 1999; Gibbons and Murphy, 1992). The purpose of the model is not to analyse complex incentive mechanisms able to induce agents' virtuous and efficient behaviour, but to describe how simple design choices related to the dynamics of reputation and "incapacitation" based on the portability of reputation (i.e., a ban from operating on ridesharing platforms, imposed on the basis of reputation metrics) could change agents' strategic behaviour.

The model applies to both centralized and decentralized platforms. Centralized platforms may use ratings to reward providers complying with the behavioural standards they set by matching compliant providers to higher-value rides (i.e., longer rides, or a higher number of rides). In decentralized platforms, riders may reward compliance with the platform's behavioural standards by choosing drivers with higher ratings. In both cases, the platform may exclude providers if their rating falls below a given threshold. Throughout, we assume away any problem in rating formation of the type considered in the extant literature (e.g., cognitive or strategic biases), so that reviews are able to fully capture providers' performance.

The following figure illustrates graphically the relationship among the stakeholders at the basis of the model. 
[INSERT FIG.1 ABOUT HERE]

\subsection{Drivers' Optimal Choice in A Single Period}

Let us assume that drivers obtain income $Y=\bar{C}$ from participation to the platform ${ }^{6}$ and have an initial rating, or endowment of reputation, $\bar{R}=100$. In any given period $t$, providers maximize their utility $U(t)(B(t), C(t))$, where $B$ indicates an economic benefit that can be obtained by consuming reputation and $C$ is the consumption level of the representative good that has price 1 . In other words, drivers value the opportunity not to comply with the behavioural standards set by the platform (the economic benefit $B$ ) and can obtain it by taking actions that reduce reputation, e.g. reducing the level of service quality so as to save on their effort. $R$ is the amount of rating/reputation lost because lack of service quality induces bad reviews from riders.

In the optimization problem we assume a number of platforms sufficiently large and a time horizon sufficiently long, so that drivers face a situation that can be considered similar to a continuum of platforms.

Depleting the initial rating endowment $\bar{R}$ entails a loss of consumption for the driver equal to $\alpha(R(t)) \geq 0$, where $\alpha_{R}>0, \alpha_{R R}>0$. This may be because a centralized platform matches the driver to lower-value rides or because users/riders reduce their propensity to source services from drivers with a low reputation. We assume that the consumption loss for the provider increases in the amount of reputation $R$ that is depleted. Thus, providers can obtain $B$ by using reputation scores and incurring the consumption loss $\alpha(R(t))$. The case $\alpha(R(t))=0$ corresponds to a system in which the platform does not use ratings to influence providers' remuneration.

For the sake of simplicity, it is assumed that $B(t)=100-R(t)$. When $R=\bar{R}=0$, the threshold of reputation that determines expulsion from the platform is reached.

Table 3 provides an overview of the symbols and notation used.

[INSERT TABLE 3 ABOUT HERE]

\footnotetext{
${ }^{6}$ We treat it as an endowment, as we are not interested in the level of activity on the platform.
} 
The problem of the user/driver in any single period $t$ can be represented as follows:

$\operatorname{Max} U(t)(B(t), C(t))$

s.t. $\alpha(R(t)) *(100-R(t))+C(t)=\bar{C}$

Since $B(t)=100-R(t)$, the problem can be written as

$\operatorname{Max} U(t)(B(t), C(t))$

s.t. $\alpha(R(t)) * B(t)+C(t)=\bar{C}$

In the next two subsections we consider the more general problem of optimal inter-temporal use of rating points in order to obtain the economic benefit $B$ in two different stylized scenarios. In the first, switching across platforms is assumed not to be possible, so that exclusion from the platform entails that drivers have to renounce to their P2P activity altogether; in the second, drivers excluded from a platform may switch continuously to a different platform and continue to provide services through the new platform.

\subsection{OPTIMAL INTER-TEMPORAL CHOICE With No SWITCHING ACROSS DifFERENT}

\section{PlatForms}

In a setting with multiple periods, reputation can be considered as a renewable resource. The ease with which the algorithm defined by the platform allows providers to restore reputational ratings is captured by the function $A(R(t))$. Reputation is considered a renewal function bounded above, i.e. there exists $\mathrm{E}: \mathrm{R}(\mathrm{A}) \leq \mathrm{E}$ for all $\mathrm{A}$; moreover R exhibits a threshold effect, such that there exists $\mathrm{G}$ : $R(A)=0$ for all $A \leq G$ and $R(A)$ is strictly concave for $A \geq G$ and above a given level of $A, R(A)$ is decreasing, i.e. $\mathrm{R}^{\prime}(\mathrm{A})<0$ for $\mathrm{A}>\mathrm{A}_{\mathrm{m}}$ and the possible values of $\mathrm{A}$ are bounded above (logistic function).

The optimal inter-temporal choice of providers in a scenario whereby switching across platforms is assumed not to be possible can be written as:

$$
\operatorname{Max} \int_{0}^{T} U(t)(B(t), C(t)) d t
$$

s.t. $\frac{d C}{d t}=C^{*}-\alpha(R(t))$ 


$$
\left.\frac{d R}{d t}=A(R(t))-B(t)\right)
$$

We also assume that:

$$
\text { marginal utilities increase at a decreasing rate }
$$

$U_{C}>0, U_{C C}<0, U_{B}>0, U_{B B}<0$

(ii) the cost of using reputation to obtain $\mathrm{B}$ increases at an increasing rate $\alpha_{R}>0, \alpha_{R R}>0$

(iii) $\quad A_{R}>0$ or $A_{R}<0$, where the process by which reputation is restored is a logistic function or "too much reputation could be a bad".

The solution to this optimal control problem allows us to formulate the following propositions.

Proposition 1. In the equilibrium with no switching, providers choose to "consume" the amount of reputational ratings for which the marginal rate of substitution between the economic benefit $B$ and consumption $C$ is equal to the ratio between the marginal cost of this transformation $\left(\alpha_{R}\right)$ and the rate at which the platform algorithm allows to restore reputation $\left(A_{R}\right)$.

Proposition 1 implies that, even in a setting where providers can work for a single platform and where, by assumption, the platform-mediated rating system is able to perfectly capture service quality, reputational ratings nonetheless fail to induce perfect compliance with the behavioural standards set by platforms. Drivers will tend to consume their reputational ratings in their initial periods of participation to the platform, up to the maximum amount compatible with their indifference curves, and will start being compliant only after a critical threshold of loss of reputational ratings is reached.

Indeed, when $\left|\frac{U_{B}}{U_{C}}\right|>\frac{\alpha_{R}}{A_{R}}$ drivers are induced to reduce compliance with the behavioural standards set by the platform.

The solution to the model also indicates that the extent to which ratings are effectively linked to remuneration and the extent to which the platform's algorithm makes it hard to restore reputation can be considered complementary tools to induce compliance with the platform's behavioural rules and create incentives for agents to provide service quality. This conclusion is summarized in the following proposition: 
Proposition 2. Other things being equal, and particularly for any given level of the marginal cost of transforming reputational ratings in $B\left(\alpha_{R}\right)$, a decrease in the rate at which the platform algorithm allows to restore reputation $\left(A_{R}\right)$ induces an increase in compliance. Similarly, other things being equal, and particularly for any given level of $A_{R}$, an increase in $\alpha_{R}$ induces an increase in compliance.

The first part of Proposition 2 suggests that an increase in compliance may be achieved by increasing the opportunity cost of reintegrating the endowment of reputation. This may be done by appropriately designing the platform's algorithm or by influencing providers' perception of the magnitude of this cost. The second part refers to the standard idea that linking ratings/performance to remuneration may help achieve incentive compatibility.

\subsection{OPTIMAL INTER-TEMPORAL CHOICE WITH "CONTINUOUS SWITCHING" ACROSS}

\section{DifFERENT PlatForms}

The optimal inter-temporal choice by providers that, if excluded from a platform, may acquire a new endowment of reputation by switching continuously to different platforms, may be represented as indicated below. For the sake of simplicity, we assume that $A_{R}=0$.

$$
\operatorname{Max} \int_{0}^{T} U(t)(B(t), C(t)) d t
$$

s.t. $\frac{d C}{d t}=C^{*}-\alpha(R(t))$

In this case providers choose a dissipative (so-called 'bang-bang') strategy involving the depletion of reputation and the jump to a different platform. It is important to stress that this is independent of the design of the rating system, and particularly of the choice of the maximum amount of reputational points and the rate at which the platform algorithm allows to restore reputation. At any time, agents are only concerned with whether there is a new platform to switch to and face a discrete choice between consuming and not consuming their total reputation on the current platform. The 
amount of reputation still available for 'consumption', as well as the rate at which they may be restored, are irrelevant to their choice.

The solution to this optimal control problem can be summarized in the following:

Proposition 3. In the continuous switching equilibrium, providers consume at any period $t$ before the terminal period $T$ the entire amount of their reputational ratings, independently of the amount of ratings with which they are endowed.

Proposition 3 entails that the design of the rating system is irrelevant as an incentive device if providers can acquire a new endowment of reputation by continuously switching across different platforms. Thus, in circumstances in which local competition among different platforms impairs the effectiveness of any of the platforms' rating systems as an incentive device, it is in the platform's interest to devise ways to reduce providers' ability to acquire a new endowment of reputation through switching. Limiting this ability increases providers' compliance with the platform's behavioural standards.

\section{DISCUSSION AND POLICY IMPLICATIONS}

The simple model presented above allows to capture a number of features of platform-mediated rating systems that affect incentives to comply with the behavioural standards set by the platform and therefore to provide service quality.

The model highlights that the threat of exclusion from the platform per se is not sufficient to induce perfect compliance, even if riders' reviews perfectly represent providers' quality of service and even if drivers cannot switch to a different platform. This is because the structure of providers' intertemporal preferences creates incentives to deplete their reputation according to their rate of substitution between income and reputation (or the ratio between the economic benefit obtainable by depletion of reputation and consumption of standard goods) and may thus induce less than perfect compliance. 
Moreover, the model shows that the choice of the threshold that triggers exclusion from the platform is irrelevant when providers can switch among multiple platforms, as long as they are aware of this threshold.

This conclusion is relevant in view of the lively debate that has emerged on the issue whether platform's self-regulation is sufficient to address consumer protection and security issues that, in the offline world, are addressed through state regulation. A key aspect of this debate has to do exactly with the incentive effects of P2P platforms' reputation systems, which some argue to be fully adequate to address potential ex post transaction risks (Allen and Berg, 2014; Thierer et al., 2015). Our model suggests some caution with respect to the conclusion that platforms' self regulation is a full substitute for (or even an unequivocally better solution than) public regulation since it can fully solve incentive problems due to asymmetric information.

The model has also more direct implications for the design of control mechanisms by sharing platforms. The multiple case study analysis proposed in section 2 has highlighted that, in decentralized $\mathrm{P} 2 \mathrm{P}$ platforms, the link between remuneration and performance is relatively direct and clear-cut because platform users do normally take reputational ratings into account when choosing service providers. Centralized shared mobility platforms, by contrast, do not currently make substantial recourse to incentive systems linking remuneration to performance. This may be because of intrinsic limits to the possibility of linking ratings to remuneration in the shared mobility sector due to the fact that, in many areas in which $\mathrm{P} 2 \mathrm{P}$ ridesourcing services are still in a take-up phase, territorial coverage is a more prominent concern than quality of service. With increased penetration of $\mathrm{P} 2 \mathrm{P}$ mobility services, however, the chances of being able to use the lever of the link between ratings and remuneration as an incentive device also in centralized platforms are likely to increase.

The relatively instantaneous nature of the $\mathrm{P} 2 \mathrm{P}$ ridesourcing transaction is also critical for the incentive effect of reputational ratings. While it is true that riders have the option to reject a provider in the first few seconds after the centralized platform has proposed a "match", so that low reputation may translate into a lower number of rides, and therefore lower overall earnings, anecdotal evidence indicates that this has so far not frequently occurred. Indeed, P2P ridesourcing services have an advantage over traditional mobility services exactly in circumstances in which riders may be reluctant 
to reject a provider, i.e. when they cover geographically dispersed areas or ensure availability at times of peak demand.

Whatever the current limitation to the use of incentive systems, our model suggests that the threat of exclusion exercised by the platform should always be complemented by reliance on measures linking ratings to remuneration for the purposes of providing incentives.

This has implications also for the choice of the appropriate scale of ratings, and particularly the choice between 3/4/5- "stars-based" rating systems and a simpler "thumbs-up/thumbs-down" rating system such as the one adopted by Youtube in 2010. Whether one or the other should be chosen, if the purpose is to induce compliance, depends on whether earnings are linked to performance or not. If there is no link between earnings and performance, a simple "thumbs-up/thumbs-down" rating system, consistent with the current distribution of ratings that exhibits peaks at 1 and 5 stars (Bercovici, 2014), would convey all the relevant information from users of the service. If, by contrast, a link between earnings and performance is established, a rating system providing a more nuanced representation of users' experience would be appropriate

Moreover, the fact that the effectiveness of platform-mediated rating systems as an incentive device increases in the strength of the link between ratings/performance and remuneration and in the magnitude of the opportunity cost of reintegrating the endowment of reputation may suggest the existence of an efficiency rationale for some of their controversial features. One of those may be the fact that centralized mobility platforms tend to be very opaque in the explanation of the working of their algorithm they give to providers and to nurture in many ways the perception that restoring points is difficult, even with the consequence of accepting a reputation of 'unfairness'. This can be conceptualized as a way of increasing the perceived cost of restoring reputation.

Finally, the model highlights that incentives to comply with the platform's behavioural standards and to provide service quality are positively affected by limitations to providers' ability to acquire new endowments of reputation through switching. If this ability is impaired, the choice of the threshold by the platform becomes relevant to the incentives to provide service quality. 
One possibility to obtain this result would be to introduce reputation portability, an idea that has been the subject of some debate ${ }^{7}$. This may be done through public regulation or through private initiative. Indeed, as reported by Tadelis (2016), some private solutions aiming at implementing reputation portability through applications of blockchain technology have spontaneously emerged in the market ${ }^{8}$.

In the 'public regulation' solution, portability of reputation should be coupled with measures meant to impose costs from switching across platforms, such as for instance imposing to providers losing their reputation on one platform a period of 'incapacitation', i.e. of suspension from the possibility to work for any platform. In the 'private initiative' solution, the incentive effect of portability of reputation will be higher, the higher the homogeneity of the standards platforms choose for their rating systems. The closer the thresholds for exclusion of non-compliant providers chosen by the platforms, the less likely it is for any provider to be able to provide services on a new P2P platform if it has consumed all of its endowment of reputation on a given platform. ${ }^{9}$

Remarkably, both the 'public' and the 'private' solutions would allow to mimic in the P2P context, in absence of formal employment relationships, enforcement mechanisms based on the threat of job loss that are normally at play in employer-employee relationships.

\footnotetext{
${ }^{7}$ See, for instance, Dellarocas et al. (2006), reporting Amazon's and Ebay's decision to interrupt reciprocal portability of reputation and arguing that portability increases the effectiveness of a reputation mechanism.

${ }^{8}$ Tadelis (2016) illustrates the case of a company called 'The World Table' (https://www.worldtable.co). This company's project of portable reputation now appears to have been discontinued. More recently, a prototype new initiative of portable reputation based on blockchain technology has been launched under the name 'Work.nation' by a partnership between Cisco, uPort, The Institute for The Future and CoMakery (https://demo1.worknation.io/login).

${ }^{9}$ Note that this is an argument for portability of reputation that complements the more standard argument for portability of reputation as a tool to reduce switching costs so as to address risks of anticompetitive behaviour by platforms.
} 


\section{Appendix}

\section{Derivation of Proposition 1.}

$\operatorname{Max} \int_{0}^{T} U(t)(B(t), C(t)) d t$

s.t. $\frac{d C}{d t}=C^{*}-\alpha(R(t))$

$$
\frac{d R}{d t}=A(R(t))-B(t)
$$

$C(0)=C^{*}$

$C(T) \geq 0$

$R(0)=100$

$R(T) \geq 0$

$\lambda(t) \geq 0$

$\mu(t) \geq 0$

$\lambda(T) C(T)=0$

$\mu(T) C(T)=0$

The Hamiltonian for the optimal control problem indicated in (1) is:

$H=U(t)(B(t), C(t))+\lambda(t)\left(C^{*}-\alpha(R(t))+\mu(t)[A(R(t))-B(t)]\right.$

Then FOC:

$\frac{d H}{d R}=-\lambda(t) \alpha_{R}+\mu(t) A_{R}=0$ or $\lambda(t) \alpha_{R}=\mu(t) A_{R}$

$\frac{d \lambda}{d t}=\lambda^{\prime}(t)=-\frac{d H}{d C}=-U_{C}-\lambda(t)=0$ or $\quad U_{C}=-\lambda(t)$

(the co-state variable or Lagrange multiplier - shadow price or shadow value - measures the imputed value of stock accumulated - state variable - and economically is interpreted as the marginal value of increasing the state variable at a given point in time $t$ )

$\frac{d \mu}{d t}=\mu^{\prime}(t)=-\frac{d H}{d B}=-U_{B}-\mu(t)=0$ or $U_{B}=-\mu(t) \quad$ (co-state variable)

By rearranging the first of these expressions we get the optimal solution: 


$$
A_{R}=\frac{\lambda(t)}{\mu(t)} \alpha_{R} \text { or } \frac{A_{R}}{\alpha_{R}}=\frac{\lambda(t)}{\mu(t)}
$$

\section{Derivation of Proposition 2.}

$\operatorname{Max} \int_{0}^{T} U(t)(B(t), C(t)) d t$

s.t. $\frac{d C}{d t}=C^{*}-\alpha(R(t))$

$0 \leq R(t) \leq 100$

$C(0)=C^{*}$

$C(T) \geq 0$

$R(0)=100$

$R(T) \geq 0$

$\lambda(t) \geq 0$

$\lambda(T) C(T)=0$

Assuming that preferences are linear and additive, at least piece-wise, then:

$-\frac{d H}{d C}=\frac{d \lambda}{d t}=0$ and $-\frac{d H}{d B}=\frac{d \mu}{d t}=0$

Equations (A1) and (A2) can be written as:

$\frac{d \lambda}{d t}=\lambda^{\prime}(t)=-\frac{d H}{d C}=-U_{C}-\lambda(t)=0$ or $-U_{C}=\lambda(t) \quad$ (co-state variable)

$\frac{d \mu}{d t}=\mu^{\prime}(t)-\frac{d H}{d B}=-U_{B}+\mu(t)=0$ or $U_{B}=\mu(t) \quad$ (co-state variable)

Substituting (A5) and (A6) in Eq. (A4) for the optimal solution, we obtain that:

$\frac{\alpha_{R}}{A_{R}}=\frac{U_{B}}{-U_{C}}=-\frac{U_{B}}{\gamma U_{C}}$ or $\left|\frac{U_{B}}{U_{C}}\right|=\frac{\alpha_{R}}{A_{R}}$ 


\section{Derivation of Proposition 3.}

The Hamiltonian for the optimal control problem indicated in (2) is:

$H=U(t)(B(t), C(t))+\lambda\left[C^{*}-\alpha(R(t))\right]+\mu_{1}(100-R(t))+\mu_{2} R(\mathrm{t})$

From FOC, the optimal solution satisfies:

$\frac{d H}{d R}=-\lambda(t) \alpha_{R}-\mu_{1}(t)+\mu_{2}(t)$

$\frac{d \lambda}{d t}=\lambda^{\prime}(t)=-\frac{d H}{d C}=-U_{C}-\lambda(t)$

(co-state variable) (A9)

$\mu_{1}(t) \geq 0 ; \mu_{1}(t)(R(t)-100)=0$ and $\mu_{2}(t) \geq 0 ; \mu_{2}(t) R(t)=0 \quad$ (co-state variable) $\quad$ (A10)

Finally by Kuhn-Tucker's complementary slackness Transversality Conditions or Boundary

Conditions (i.e. do not leave a valuable resource unused unless it is costless to do so) the following is derived:

$\left\{\begin{array}{l}R=100 \text { if } \lambda=0 \\ R=0 \text { if } \quad \lambda>0\end{array}\right.$ 


\section{References}

Allen, D., Berg, C., 2014. The sharing economy: How over-regulation could destroy an economic revolution, Fast Company. https://doi.org/10.1177/1536504214567860.WINTER

Andreoni, J., Rao, J.M., 2011. The power of asking: How communication affects selfishness, empathy, and altruism. J. Public Econ. 95, 513-520. https://doi.org/10.1016/j.jpubeco.2010.12.008

Avery, C., Resnick, P., Zeckhauser, R., 1999. The market for evaluations. Am. Econ. Rev. 89, 564584. https://doi.org/10.1257/aer.89.3.564

Ba, S., Pavlou, P.A., 2002. Evidence of the Effect of Trust Building Technology in Electronic Markets: Price Premiums and Buyer Behavior. MIS Q. 26, 243. https://doi.org/10.2307/4132332

Basili, M., Belloc, F., Nicita, A., 2015. Group attitude and hybrid sanctions: Micro-econometric evidence from traffic law. Transp. Res. Part A Policy Pract. 78, 325-336. https://doi.org/10.1016/j.tra.2015.05.019

Bente, G., Dratsch, T., Kaspar, K., Häßler, T., Bungard, O., Al-Issa, A., 2014. Cultures of trust: Effects of avatar faces and reputation scores on German and Arab players in an online trust-game. PLoS One 9. https://doi.org/10.1371/journal.pone.0098297

Bercovici, J., 2014. Uber's Ratings Terrorize Drivers And Trick Riders . Why Not Fix Them ? Forbes. Bolton, G.E., Greiner, B., Ockenfels, A., 2013. Engineering Trust - Reciprocity in the Production of Reputation Information. Manage. Sci. 59, 265-285. https://doi.org/10.1287/mnsc.1120.1609

Botsman, R. Rogers, R., 2010. What Is Mine Is Yours: How Collaborative Consumption is Changing The Way We Live. Harpers Collins, London.

Botsman, R., 2013. The Sharing Economy Lacks A Shared Definition | Co.Exist | Ideas + Impact [WWW Document]. URL https://www.fastcoexist.com/3022028/the - sharing - economy lacks - a - shared - definition\#10 (accessed 10.11.18).

Boudreau, K., Hagiu, A., 2009. Platform Rules: Multi-Sided Platforms as Regulators, in: Gawer, A. (Ed.), Platforms, Markets and Innovation. Edward Elgar Publishers, Cheltenham, UK.

Cabral, L., Hortacsu, A., 2010. The dynamics of seller reputation: Evidence from ebay. J. Ind. Econ. 58, 54-78. https://doi.org/10.1111/j.1467-6451.2010.00405.x 
Chen, L., Jiang, T., Li, W., Geng, S., Hussain, S., 2017. Who should pay for online reviews? Design of an online user feedback mechanism. Electron. Commer. Res. Appl. 23, 38-44. https://doi.org/10.1016/j.elerap.2017.04.005

Constantiou, I., Marton, A., Tuunainen, V.K., 2017. Four Models of Sharing Economy Platforms. MIS Q. Exec. 16, 231-251.

Dai, W. (Daisy), Jin, G., Lee, J., Luca, M., 2018. Aggregation of consumer ratings: an application to Yelp.com. Quant. Mark. Econ. 16, 289-339. https://doi.org/10.1007/s11129-017-9194-9

Dardanoni, V., 1988. Optimal choices under uncertainty: the case of two-argument utility functions. Econ. J. 98, 429-450.

de Langhe, B., Fernbach, P.M., Lichtenstein, D.R., 2016. Navigating by the stars: Investigating the actual and perceived validity of online user ratings. J. Consum. Res. 42, 817-833. https://doi.org/10.1093/jcr/ucv047

De Reuver, M., Sørensen, C., Basole, R.C., 2018. The digital platform: A research agenda. J. Inf. Technol. 33, 124-135. https://doi.org/10.1057/s41265-016-0033-3

Dellarocas, C., Dini, F., Spagnolo, G., 2006. Designing reputation (feedback) mechanisms, in: Dimitri, N., Piga, G., Spagnolo, G. (Eds.), HANDBOOK OF PROCUREMENT. Cambridge University Press.

Dellarocas, C., Wood, C.A., 2008. The Sound of Silence in Online Feedback: Estimating Trading Risks in the Presence of Reporting Bias. Manage. Sci. 54, 460-476.

Dewatripont, M., Tirole, J., Jewitt, I., 1999. The Economics of Career Concerns, Part I: Comparing Information Structures. Rev. Econ. Stud. https://doi.org/10.1111/1467-937X.00084

Edelman, B., Luca, M., Svirsky, D., 2017. Racial discrimination in the sharing economy: Evidence from a field experiment. Am. Econ. J. Appl. Econ. 9, 1-22. https://doi.org/10.1257/app.20160213

Edelman, B.G., Luca, M., 2014. Digital Discrimination: The Case of Airbnb.com, Ssrn. https://doi.org/10.2139/ssrn.2377353

Einav, L., Farronato, C., Levin, J., 2016. Peer-to-Peer Markets, Ssrn. https://doi.org/10.1146/annureveconomics-080315-015334 
Ert, E., Fleischer, A., Magen, N., 2016. Trust and reputation in the sharing economy: The role of personal photos in Airbnb. Tour. Manag. 55, 62-73. https://doi.org/10.1016/j.tourman.2016.01.013

Evans, D.S., 2011. Governing Bad Behavior by Users of Multi-Sided Platforms. Ssrn 27, 1201. https://doi.org/10.2139/ssrn.1950474

Fradkin, A., Grewal, E., Holtz, D., Pearson, M., 2015. Bias and Reciprocity in Online Reviews, in: Proceedings of the Sixteenth ACM Conference on Economics and Computation - EC '15. pp. 641-641. https://doi.org/10.1145/2764468.2764528

FTC, 2015. FTC The Sharing Economy Workshop transcript segment 3 - June 9, 2015. The "Sharing" Economy Workshop transcript segment 2 - June 9, 2015, transcript segment 3 - June 9, 2015. The "Sharing" Economy Workshop transcript segment 2 - June 9, 2015.

Fudenberg, D., Tirole, J., 1990. Moral Hazard and Renegotiation in Agency Contracts. Econometrica. https://doi.org/10.2307/2938317

Gibbons, R., Murphy, K.J., 1992. Optimal Incentive Contracts in the Presence of Career Concerns: Theory and Evidence. J. Polit. Econ. https://doi.org/10.1086/261826

Gibbons, R., Roberts, J., 2010. Incentives in organizations, in: Gibbons, R., Roberts, J. (Eds.), Handbook of Organizational Economics. North-Holland, Amsterdam.

Gilbert, E., Karahalios, K., 2009. Predicting tie strength with social media. Proc. 27th Int. Conf. Hum. factors Comput. Syst. - CHI 09 211. https://doi.org/10.1145/1518701.1518736

Gregg, D.G., Scott, J.E., 2006. The Role of Reputation Systems in Reducing On-Line Auction Fraud. Int. J. Electron. Commer. 10, 95-120. https://doi.org/10.2753/JEC1086-4415100304

Hawlitschek, F., Notheisen, B., Teubner, T., 2018. The limits of trust-free systems: A literature review on blockchain technology and trust in the sharing economy. Electron. Commer. Res. Appl. 29, 50-63. https://doi.org/10.1016/j.elerap.2018.03.005

Hendrikx, F., Bubendorfer, K., Chard, R., 2015. Reputation systems: A survey and taxonomy. J. Parallel Distrib. Comput. 75, 184-197. https://doi.org/10.1016/j.jpdc.2014.08.004

Holmstrom, B., 1979. Moral Hazard and Observability. Bell J. Econ. https://doi.org/10.2307/3003320 Holmstrom, B., Milgrom, P., 1987. Aggregation and Linearity in the Provision of Intertemporal 
Incentives. Econometrica. https://doi.org/10.2307/1913238

Horton, J.J., Stern, L.N., Golden, J.M., 2015. Reputation inflation: Evidence from an online labor market. Work. Pap. 1-31.

Jøsang, A., Ismail, R., Boyd, C., 2007. A survey of trust and reputation systems for online service provision. Decis. Support Syst. 43, 618-644. https://doi.org/10.1016/j.dss.2005.05.019

Jurca, R., Faltings, B., 2003. An incentive compatible reputation mechanism, in: Proceedings - IEEE International Conference on E-Commerce, CEC 2003. pp. 285-292. https://doi.org/10.1109/COEC.2003.1210263

Katz, V., 2015. REGULATING THE SHARING ECONOMY. Berkeley Technol. Law J. 30, 10671126. https://doi.org/10.14763/2016.2.414

Lauterbach, D., Truong, H., Shah, T., Adamic, L., 2009. Surfing a web of trust: Reputation and reciprocity on Couchsurfing.com, in: Proceedings - 12th IEEE International Conference on Computational Science and Engineering, CSE 2009. pp. 346-353. https://doi.org/10.1109/CSE.2009.345

Li, X., Guo, X., Wang, C., Zhang, S., 2016. Do buyers express their true assessment? Antecedents and consequences of customer praise feedback behaviour on Taobao. Internet Res. 26, 1112-1133. https://doi.org/10.1108/IntR-03-2015-0063

Liu, L., Munro, M., 2012. Systematic analysis of centralized online reputation systems. Decis. Support Syst. 52, 438-449. https://doi.org/10.1016/j.dss.2011.10.003

Luca, M., 2016. Designing Online Marketplaces: Trust and Reputation Mechanisms (No. 17-017). https://doi.org/10.3386/w22616

Malaga, R.A., Smith, R.H., 2001. Web-Based Reputation Management Systems: Problems and Suggested Solutions. Electron. Commer. Res. 1, 403-417. https://doi.org/10.1023/A:1011557319152

Mauri, A.G., Minazzi, R., Nieto-García, M., Viglia, G., 2018. Humanize your business. The role of personal reputation in the sharing economy. Int. J. Hosp. Manag. 73, 36-43. https://doi.org/10.1016/j.ijhm.2018.01.017

Mazzella, F., Sundararajan, A., Butt d'Espous, V., Möhlmann, M., 2016. How Digital Trust Powers 
the Sharing Economy: The Digitization of Trust. IESE Insight 24-31. https://doi.org/10.15581/002.ART-2887

Miller, N., Resnick, P., Zeckhauser, R., 2005. Eliciting Informative Feedback: The Peer-Prediction Method. Manage. Sci. 51, 1359-1373. https://doi.org/10.1287/mnsc.1050.0379

Nosko, C., Tadelis, S., 2015. The Limits of Reputation in Platform Markets: An Empirical Analysis and Field Experiment. NBER Work. Pap. Ser. https://doi.org/10.3386/w20830

Nunley, J.M., Owens, M.F., Howard, R.S., 2011. The effects of information and competition on racial discrimination: Evidence from a field experiment. J. Econ. Behav. Organ. 80, 670-679. https://doi.org/https://doi.org/10.1016/j.jebo.2011.06.028

Rayle, L., Shaheen, S., Chan, N., Dai, D., Cervero, R., 2013. App-Based, On-Demand Ride Services: Comparing Taxi and Ridesourcing Trips and User Characteristics in San Francisco, Journal of Chemical Information and Modeling. https://doi.org/10.1017/CBO9781107415324.004

Resnick, P., Kuwabara, K., Zeckhauser, R., Friedman, E., 2000. Reputation systems. Commun. ACM 43, 45-48. https://doi.org/10.1145/355112.355122

Schor, J.B., Fitzmaurice, C.J., 2015. Collaborating and connecting: the emergence of the sharing economy, in: Reisch, L., Thogersen, J. (Eds.), Handbook of Research on Sustainable Consumption. Elgar, Cheltenham, pp. 410-425. https://doi.org/10.4337/9781783471270.00039

Shaheen, S., Cohen, A., 2018. Shared ride services in North America: definitions, impacts, and the future of pooling. Transp. Rev. 1-16. https://doi.org/10.1080/01441647.2018.1497728

Standing, C., Standing, S., Biermann, S., 2018. The implications of the sharing economy for transport. Transp. Rev. 1-17. https://doi.org/10.1080/01441647.2018.1450307

Sundararajan, A., 2016. The Sharing Economy: The End of Employment and the Rise of CrowdBased Capitalism. MIT Press, Cambridge, Massachussets.

Tadelis, S., 2016. Reputation and Feedback Systems in Online Platform Markets. Annu. Rev. Econom. 8, 321-340. https://doi.org/10.1146/annurev-economics-080315-015325

ter Huurne, M., Ronteltap, A., Corten, R., Buskens, V., 2017. Antecedents of trust in the sharing economy: A systematic review. J. Consum. Behav. 16, 485-498. https://doi.org/10.1002/cb.1667 
Teubner, T., Hawlitschek, F., Dann, D., 2017. Price Determinants on Airbnb: How Reputation Pays Off in the Sharing Economy. J. Self-Governance Manag. Econ. 5, 53. https://doi.org/10.22381/JSME5420173

Thierer, A.D., Koopman, C., Hobson, A., Kuiper, C., 2015. How the Internet, the Sharing Economy, and Reputational Feedback Mechanisms Solve the "Lemons Problem," SSRN. https://doi.org/10.2139/ssrn.2610255

Tiwana, A., 2014. Platform Ecosystems: Aligning Architecture, Governance, and Strategy, Platform Ecosystems: Aligning Architecture, Governance, and Strategy. https://doi.org/10.1016/C2012-0$06625-2$

Tiwana, A., Konsynski, B., Bush, A.A., 2010. Platform evolution: Coevolution of platform architecture, governance, and environmental dynamics. Inf. Syst. Res. 21, 675-687. https://doi.org/10.1287/isre.1100.0323

Wallsten, S., 2015. Has Uber Forced Taxi Drivers to Step Up Their Game? Atl.

Wareham, J.D., Fox, P., Cano Giner, J.L., 2014. Technology Ecosystem Governance. Organ. Sci. 25, $1195-1215$.

Zervas, G., Proserpio, D., Byers, J., 2015. A First Look at Online Reputation on Airbnb, Where Every Stay is Above Average, SSRN. https://doi.org/10.2139/ssrn.2554500

Zhao, H., Yang, X., Li, X., 2012. An incentive mechanism to reinforce truthful reports in reputation systems.J. Netw. Comput. Appl. 35, 951-961. https://doi.org/10.1016/j.jnca.2011.03.011 
Table 1. Shared mobility platforms' business models

\begin{tabular}{|c|c|c|}
\hline Platform type & Description & Examples \\
\hline Peer to Peer Carsharing & $\begin{array}{l}\text { sharing of the use of cars or vans among } \\
\text { peers in exchange for a time-based payment } \\
\text { that refers to access to the asset rather than } \\
\text { to the driving service }\end{array}$ & Turo, GetAround and Drivy \\
\hline Ridesharing & $\begin{array}{l}\text { sharing of cars or vans among a driver/car } \\
\text { owner with a pre-defined destination and } \\
\text { one or more riders with a compatible origin- } \\
\text { destination combination, in exchange for the } \\
\text { sharing of expenses and sometimes of } \\
\text { driving responsibility }\end{array}$ & BlaBlaCar and Liftshat \\
\hline Ridesourcing & $\begin{array}{l}\text { on-demand transportation service provided } \\
\text { to one or more riders (in this case defined as } \\
\text { ridesplitting) by a driver/car owner that does } \\
\text { not have a pre-defined destination and } \\
\text { behaves as a semi-professional or } \\
\text { professional service provider }\end{array}$ & Uber and Lyft \\
\hline Hybrid Services & $\begin{array}{l}\text { on-demand transportation service provided } \\
\text { to one or more riders by a traditional taxi } \\
\text { service provider through apps and } \\
\text { technologies typical of ridesourcing }\end{array}$ & GetTaxi and MyTaxi \\
\hline
\end{tabular}


Table 2. Overview of rating systems in a selected sample of shared mobility platforms

\begin{tabular}{|c|c|c|c|}
\hline \multicolumn{4}{|c|}{ Decentralized platforms } \\
\hline & Certification/verification & Scale of rating & Type of rating system \\
\hline \multicolumn{4}{|c|}{ P2P CARSHARING } \\
\hline Turo & $\begin{array}{l}\text { - Users' personal information certified by } \\
\text { the platform and sometimes verified } \\
\text { through external references ("approved } \\
\text { driver") } \\
\text { - Link to Facebook and Google+ }\end{array}$ & - Ratings on a scale 1-5 & $\begin{array}{l}\text { Two-way double blind ratin, } \\
\text { with publication of users' } \\
\text { ratings }\end{array}$ \\
\hline GetAround & $\begin{array}{l}\text { - Users' personal information verified by the } \\
\text { platform through Facebook, Credit Bureau } \\
\text { and other } 16 \text { references, but not certified } \\
\text { - Link to Facebook }\end{array}$ & $\begin{array}{l}\text { - Ratings and feedbacks } \\
\text { controlled by the } \\
\text { platform } \\
\text { - Ratings on a scale } 1-4 \text { for } \\
\text { riders, yes/no/don't know } \\
\text { for renters }\end{array}$ & $\begin{array}{l}\text { Two-way rating system, ra } \\
\text { neither published nor commur } \\
\text { contractual parties }\end{array}$ \\
\hline Drivy & $\begin{array}{l}\text { - Users' personal information verified by the } \\
\text { platform, but not certified through a 'tag' } \\
\text { - Link to Facebook }\end{array}$ & - Ratings on a scale $1-5$ & $\begin{array}{llr}\text { Two-way rating } & \text { system } \\
\text { publication of users' } & \text { rati } \\
\text { comments } & & \\
\end{array}$ \\
\hline \multicolumn{4}{|c|}{ RIDESHARING } \\
\hline BlaBlaCar & $\begin{array}{l}\text { - Users' personal information certified by } \\
\text { the platform } \\
\text { - Link to Facebook and LinkedIn }\end{array}$ & $\begin{array}{l}\text { - Ratings to drivers and } \\
\text { riders on a scale } 1-5 \\
\text { - Additional rating to } \\
\text { drivers on a scale } 1-3 \text { for } \\
\text { driving ability }\end{array}$ & $\begin{array}{l}\text { Two-way double blind ratin } \\
\text { with publication of users' } \\
\text { ratings and comments; comme } \\
\text { by only one party to the tr } \\
\text { published after a 14-days emb; }\end{array}$ \\
\hline Lyftshare & $\begin{array}{l}\text { - Users' personal information certified by } \\
\text { the platform } \\
\text { - Link to Facebook }\end{array}$ & $\begin{array}{l}\text { - Ratings to drivers and } \\
\text { riders on a scale } 1-5\end{array}$ & $\begin{array}{l}\text { Two-way rating } \\
\text { publication of users' } \\
\text { and comments }\end{array}$ \\
\hline \multicolumn{4}{|c|}{ Centralized platforms } \\
\hline & Certification/verification & Scale of rating & Type of rating system \\
\hline \multicolumn{4}{|c|}{ RIDESOURCING } \\
\hline Uber & $\begin{array}{l}\text { - Drivers' personal information verified by } \\
\text { the platform/no verification on riders } \\
\text { - Link to Facebook, Spotify and Pandora }\end{array}$ & $\begin{array}{l}\text { - Ratings to drivers and } \\
\text { riders on a scale } 1-5\end{array}$ & $\begin{array}{l}\text { Two-way anonymous rating } \\
\text { with obligation to provide a } \\
\text { riders for drivers only }\end{array}$ \\
\hline Lyft & $\begin{array}{l}\text { - Drivers' personal information verified by } \\
\text { the platform/ no verification on riders } \\
\text { - Link to Facebook }\end{array}$ & $\begin{array}{l}\text { - Ratings to drivers and } \\
\text { riders on a scale } 1-5+ \\
\text { question on what element } \\
\text { of the ride was negatively } \\
\text { assessed } \\
\text { - Ratings to riders below } 4 \\
\text { should be motivated in } \\
\text { writing }\end{array}$ & $\begin{array}{l}\text { Two-way anonymous rating } \\
\text { with obligation to provide a } \\
\text { riders for drivers only }\end{array}$ \\
\hline \multicolumn{4}{|c|}{ HYBRID SERVICES } \\
\hline GetTaxi & $\begin{array}{l}\text { - Drivers' personal information verified by } \\
\text { the platform/ riders can even use } \\
\text { nicknames } \\
\text { - No link to social networks profiles }\end{array}$ & $\begin{array}{l}- \text { Ratings on a scale } 1-5 \text { to } \\
\text { drivers only }\end{array}$ & One-way rating system \\
\hline MyTaxi & $\begin{array}{l}\text { - Drivers' personal information verified by } \\
\text { the platform/ no verification on riders }\end{array}$ & $\begin{array}{l}\text { - Ratings on a scale } 1-5 \text { to } \\
\text { drivers and their cars }\end{array}$ & One-way rating system \\
\hline
\end{tabular}




\begin{tabular}{|l|l|l|l}
\hline & $\bullet$ Link to Facebook & only & \\
\hline
\end{tabular}


Table 3. Symbols and notation used in the model

\begin{tabular}{|l|l|}
\hline$B$ & economic benefit that can be obtained by consuming reputation \\
\hline $\bar{C}$ & maximum amount of consumption of the representative good available to drivers \\
\hline$C$ & consumption level chosen by drivers \\
\hline $\bar{R}$ & initial rating or endowment of reputation \\
\hline$R$ & amount of rating/reputation lost by drivers because of bad reviews from riders \\
\hline$U(B, C)$ & drivers' utility function \\
\hline$Y$ & income from participation to the platform \\
\hline$\alpha(R)$ & consumption loss for the agent due to the loss of reputation \\
\hline$\gamma$ & rate of technical transformation of reputation ratings into the economic benefit $B$ \\
\hline
\end{tabular}




\section{Highlights}

- A multiple case study of 9 ridesharing platforms highlights features of reputation-based control mechanisms

- An inter-temporal choice model analyses their effects on drivers' compliance with the platform's behavioural standards

- Compliance is imperfect even with perfect reviews and even if drivers cannot switch across platforms

- The choice of scale of rating and of the threshold for exclusion is irrelevant for incentives if drivers can switch across platforms

- Compliance can be increased by linking remuneration to performance and by raising the opportunity cost of reintegrating the endowment of reputation

- Uncertainty as to the operation of the algorithm and portability of reputation may be efficiencyenhancing 